\title{
A influência do grau de maturidade no compartilhamento de conhecimentos para melhoria da qualidade
}

The influence of the maturity degree in sharing knowledge for quality improvement

\author{
Robson Luiz Montanari \\ Luiz Alberto Pilatti
}

\section{Resumo}

O presente estudo de caso teve por objetivo investigar a influência da maturidade das equipes na qualidade dos serviços prestados por uma empresa de médio porte. A metodologia aplicada para investigação de sete equipes foi qualitativa por meio de entrevistas e observações não participantes, bem como quantitativa, com aplicação de dois questionários. Foram identificadas equipes com diferentes graus de maturidade: uma pseudo-equipe ou grupo de trabalho com baixa maturidade, quatro com potencial de amadurecimento e duas mais maduras. Foi investigada a influência do grau de maturidade no compartilhamento de conhecimentos tácitos para melhoria da qualidade dos serviços prestados em dois momentos. No primeiro para captura das diferentes percepções das equipes e dos gerentes. As equipes com maior grau de maturidade são mais predispostas a compartilhar conhecimentos tácitos e contribuem para a melhoria da qualidade dos serviços prestados.

Palavras Chaves: Equipes, Maturidade de Equipes, Gestão do Conhecimento; Qualidade.

\begin{abstract}
The current case study aimed at investigating the influence of teams' maturity in the quality of services provided by a midsize company. The methodology used for investigation of seven teams was qualitative through interviews and non-participant observations, as well as quantitative, with application of two questionnaires. The teams were identified with different degrees of maturity: a pseudo team or working group with low maturity, four teams with potential maturity and two ones with high maturity. The influence of the maturity degree on sharing tacit knowledge to improve the quality of services on two occasions was investigated. The first one was used to capture the different perceptions of the teams and of the managers. Teams with higher levels of maturity are more likely to share tacit knowledge and contribute for the improvement of the quality of provided services.
\end{abstract}

Keywords: Teams, Teams' Maturity, Knowledge Management, Quality. 


\section{Introdução}

Uma idéia equivocada, e que talvez seja justamente a maior razão do fracasso da formação de equipes, é a crença praticamente universal dos executivos na existência de apenas um tipo de equipe. Essa constatação foi feita por Peter Drucker (2001). Para o autor, existem três tipos de equipes, "cada uma diferente em sua estrutura, no comportamento que exige de seus membros, nas suas forças, vulnerabilidade, limitações e exigências, mas acima de tudo naquilo que pode fazer e que deve ser usado" (DRUCKER, 2001, p. 59).

Não obstante, as literaturas comerciais influenciam as empresas a desenvolverem o trabalho em equipe; na prática, porém, observa-se que pouco se sabe sobre implantar ou utilizar equipes para obter o máximo desempenho conjunto (BEJARANO, 2008). Na visão de Claver-Cortés et al. (2007), o cenário é de mudanças, e as empresas estão buscando, nas estruturas mais flexíveis, subsídios para superar as adversidades diárias e gerar novos conhecimentos.

Neste contexto e diante da crescente utilização da gestão baseada em equipes na estrutura organizacional, como enfatizam Sacomano Neto e Escrivão Filho (2000) e Bejarano (2006), mudanças no ambiente laboral tornam-se fundamentais. Faz-se necessária uma investigação sobre esse tema, a fim de entender as relações que envolvem o trabalho em equipe e as diferentes nomenclaturas de equipes presentes no ambiente produtivo.

Em se tratando de diferentes tipos de equipes, um fator a considerar é a maturidade. Hersey e Blanchard (1986) e Katzenbach e Smith (1994) abordam este fator de acordo com a evolução de desempenho. Para Hersey e Blanchard (1986), uma equipe ou uma pessoa passa por diferentes graus de maturidade não se podendo rotular de forma absoluta as equipes ou pessoas, como maduras ou imaturas. Katzenbach e Smith (1994) sugerem que as equipes experimentam evolução nos seus processos de amadurecimento.

O objetivo do presente artigo é identificar a influência da maturidade das equipes na qualidade dos serviços prestados por uma prestadora de serviços no Estado do Paraná.

\section{A maturidade das equipes}

A maturidade é abordada por alguns autores - Hersey e Blanchard (1986) e Katzenbach e Smith (1994) - como um fator para graduação e classificação do desempenho das pessoas e equipes. Para Hersey e Blanchard (1986 p.187), "a maturidade é a capacidade e a disposição das pessoas de assumir a responsabilidade de dirigir seus próprios comportamentos, devendo estas variáveis de maturidade serem consideradas somente em relação a uma tarefa específica a ser realizada".

A maturidade está relacionada a duas dimensões. A primeira com a do trabalho, associada esta à capacidade de fazer alguma coisa. Refere-se ao conhecimento e à capacidade técnica. As pessoas com alta maturidade de trabalho em uma determinada área têm o conhecimento, a capacidade e 
a experiência necessária para executarem certas tarefas sem direção da parte de outros (HERSEY e BLANCHARD 1986).

A segunda dimensão está associada à maturidade psicológica que se refere à disposição ou motivação para fazer alguma coisa. Diz respeito à confiança em si mesmo e ao empenho. As pessoas que têm alta maturidade psicológica em determinada área ou responsabilidade julgam que a responsabilidade é importante, têm confiança em si mesmas e sentem-se bem nesse aspecto do seu trabalho. Não precisam de grande encorajamento para cumprir suas tarefas (HERSEY e BLANCHARD 1986).

Em linhas gerais, o indivíduo com maturidade alta tem disposição para assumir responsabilidades em função da sua capacidade de dirigir seu próprio comportamento. O que já não ocorre com as pessoas que apresentam maturidade baixa, pois as mesmas não apresentam tal capacidade. A Figura 1 mostra a relação apresentada por Hersey e Blanchard (1986) relacionando a maturidade dos indivíduos ao estilo de liderança:

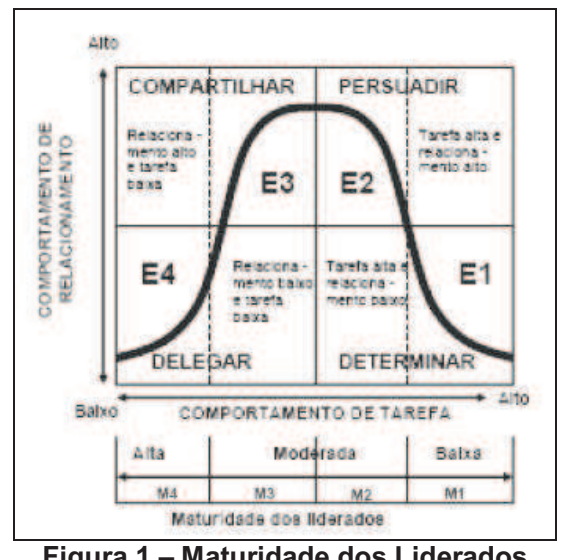

Figura 1 - Maturidade dos Liderados Fonte: Hersey e Blanchard (1986, p. 189)

Para Silva e Kovaleski (2006), a liderança situacional de Hersey e Blanchard (1986) baseia-se numa relação entre o comportamento de tarefa e relacionamento que, por sua vez, está intimamente associado à maturidade: "[...] quanto mais alto o comportamento de tarefa, mais o líder se empenha em planejar, controlar, organizar e dirigir seu subordinado; quanto mais baixo o comportamento de tarefa, mais o líder deixa estas atividades a cargo do subordinado".

Hersey e Blanchard (1986) definem maturidade não como idade ou estabilidade emocional, mas como desejo de realização, disposição para aceitar responsabilidades, capacidade e experiência relacionadas à tarefa e dividem-na em quatro níveis, a saber:

a) "M1": maturidade baixa - considera que a pessoa não tem capacidade nem vontade de assumir a responsabilidade de fazer algo, não são competentes nem seguras de si, sendo em muitos 
casos, sua falta de disposição consequência da insegurança em relação à tarefa exigida;

b) "M2": a maturidade baixa a moderada - considera que a pessoa não tem capacidade, mas sente disposição para assumir responsabilidade, tem confiança em si, no entanto, ainda não possui as habilidades necessárias;

c) "M3": maturidade moderada a alta - considera que a pessoa tem capacidade, mas não está disposta a fazer o que dela se espera. Sua falta de disposição muitas vezes é consequência da falta de confiança em si mesma ou insegurança, e

d) "M4": a maturidade alta - considera que a pessoa neste nível tem capacidade e disposição para assumir responsabilidades.

Em função da maturidade das pessoas, que sofrem variações segundo o grau de desenvolvimento e eficácia, uma abundância de nomenclaturas é apresentada na literatura disponível - Katzenbach e Smith (1994), Parker (1995) e Moscovici (2003) - que mais confunde do que esclarece a classificação das equipes. Enquanto para alguns autores qualquer grupo que trabalhe junto constitui uma equipe para outros, equipes estão associadas a valores como compartilhamento, cooperação e ajuda mútua. Para Moscovici (2003, p. 5), "um grupo transforma-se em equipe quando passa a prestar atenção à sua própria forma de operar e procura resolver os problemas que afetam seu funcionamento".

Fisher et al. (1997) discutiram diferentes percepções sobre grupos e equipes. Os resultados evidenciaram que grupos e equipes são percebidos como ativos, eficazes, energéticos e flexíveis. Entretanto, no que diz respeito às diferenças, as descrições das variáveis criativas, inovativas e bons resultados são aplicados somente às equipes. Quanto às variáveis negociar, persuasão e trabalho em rede são aplicados somente aos grupos.

Para Drucker (2001), um grupo de pessoas que trabalha junto constitui uma equipe. Ele distingue três tipos, considerando que as equipes se diferem no comportamento que exigem, naquilo que fazem melhor e naquilo que não podem fazer. Os tipos de equipes são: a) os membros têm posições fixas. Eles atuam na equipe, mas não em equipe. Por exemplo, uma equipe de beisebol ou uma linha de montagem; b) os membros têm posições fixas, mas atuam em equipe como, por exemplo, em uma equipe de futebol, e c) os membros têm posições principais ao invés de fixas. Eles devem "cobrir" seus companheiros de equipe, ajustando-se quando necessário. Por exemplo, duplas de tênis.

Em contrapartida, Salomão (1999) considera que o que caracteriza uma equipe são resultados comuns obtidos por interatividade. Equipe é quando pessoas se juntam, oferecem suas competências e conjugam esforços para fazerem coisas que são da responsabilidade do conjunto, mesmo que haja uma "chefia" que se responsabilize pelas mesmas. Sacomano Neto e Escrivão Filho (2000) mencionam que uma equipe é "um agrupamento de trabalhadores com diferentes responsabilidades funcionais, com objetivos estabelecidos, certa autonomia decisorial e multifuncionalidade dos postos de trabalho". 
Alguns dos conceitos são convergentes como os de Sacomano Neto e Escrivão Filho (2000), Salomão (1999) e Moscovici (2003), que relacionam o trabalho em equipe a objetivos comuns, ao compartilhamento de competências e de esforços. Segundo estes autores, o fato de trabalharem em conjunto não dá aos grupos, independente das posições que seus membros ocupem (fixas ou não), o status de "equipe", contrariando a opinião exposta anteriormente por Drucker (2001).

As definições de Drucker (2001), expostas anteriormente, embora divergentes com as definições de Sacomano Neto e Escrivão Filho (2000), Salomão (1999) e Moscovici (2003), dão o entendimento de uma situação que, segundo Bejarano (2006), nem sempre é suficientemente clara, pois nem todos os grupos têm a mesma finalidade. Em linhas gerais não existem justificativas para uma equipe de futebol "jogar" como uma dupla de tênis. $\mathrm{Na}$ primeira equipe existe a necessidade de trabalho interdependente enquanto na segunda, não. E também não existe justificativas para uma equipe de beisebol "jogar" como uma equipe de futebol, pois na primeira equipe o trabalho é na equipe e não em equipe.

Katzenbach (1999, p. 57) enfatiza que "a equipe de verdade segue uma disciplina simples, porém contínua para alcançar bom desempenho. Os membros devem trabalhar juntos para criar produtos de alto valor, e isso requer que o comando seja revezado entre os membros [...]". A Figura 2 ilustra a curva de desempenho de Katzenbach e Smith (1994) que sugere uma seqüência evolutiva de funcionamento dos grupos de acordo com a evolução da maturidade da equipe.

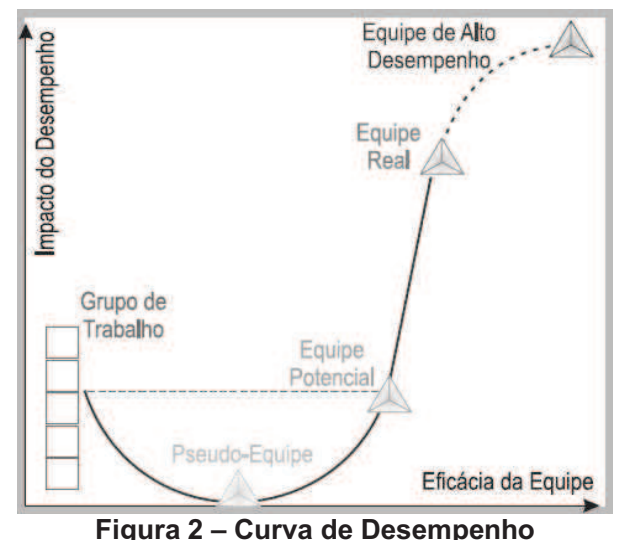

Fonte: Katzenbach e Smith (1994, p. 85)

Katzenbach e Smith (1994) classificam grupos de acordo com seu modo de funcionamento e maturidade em uma das cinco posições abaixo:

a) "Pseudo-equipe": este tipo de grupo pode definir um trabalho a se fazer, mas não se preocupa com o desempenho coletivo, nem tenta consegui-lo. As interações dos membros inibem o desempenho individual, sem produzir nenhum ganho coletivo apreciável;

b) "Grupo de trabalho": os membros desse grupo não veem nenhuma razão para se transformarem numa equipe. Podem partilhar 
informações entre si, porém, responsabilidades e objetivos, por exemplo, pertencem a cada indivíduo;

c) "Equipe potencial": este grupo quer produzir um trabalho conjunto. No entanto, os membros precisam de esclarecimentos e orientações sobre sua finalidade e objetivos;

d) "Equipe real": uma equipe real compõe-se de poucas pessoas, mas com habilidades complementares e comprometidas umas com as outras através de missão e objetivos comuns. Os membros passam a confiar uns nos outros;

e) "Equipe de alta performance": este grupo atende a todos as condições de equipe real e tem um comprometimento profundo entre seus membros com o intuito de crescimento pessoal de cada um.

Para obter a classificação dos grupos, segundo a feita por Katzenbach e Smith (1994), uma escala de maturidades das equipes foi desenvolvida por Dyer (1995). A utilização deste instrumento vem ao encontro do modelo (escala de maturidades) desenvolvido por Hersey e Blanchard (1986), chamado de teoria de liderança do ciclo vital, pois ambos são baseados na experiência de cada membro com sua equipe.

\section{Equipes: compartilhamento de experiências e qualidade na prestação de serviços}

As pessoas trabalhando em equipes interagem a partir de relações interdependentes que atuam na mudança e no estabelecimento de novos comportamentos. Essa dinâmica auxilia na construção de configurações sociais entre os homens nas equipes, as quais influenciam no desempenho e, por consequência, afetam a produtividade e desempenho organizacional que está intimamente associado ao conhecimento tácito das pessoas (MONTANARI, 2008).

O conhecimento assume uma função importantíssima na atualidade, pois as empresas passam a contar, além dos recursos que já são conhecidos como capital e mão de obra, com os conhecimentos aplicados ao trabalho e com os trabalhadores do conhecimento, denominados, segundo Drucker (2004), de knowledge workers.

Para Nonaka e Takeuchi (1997), a criação do conhecimento é um processo que ocorre dentro de uma comunidade de interação e que amplia organizacionalmente $\mathrm{o}$ conhecimento adquirido pelas pessoas. $\mathrm{O}$ conhecimento organizacional (CO) passa a ser fruto das interações que ocorrem no território empresarial que, para Fleury e Oliveira (2001), é desenvolvido por meio de aprendizagem e é o fundamento das competências essenciais da organização formadas por conhecimentos tácitos e coletivos.

Com efeito, o desafio para as organizações está em mudar a cultura já existente de modo a se criar um clima propício à mudança e ao aprendizado, pela interação dos conhecimentos tácitos e explícitos (NONAKA; TAKEUCHI, 1997). Quando essa mudança ocorre, geram-se 
conhecimentos e se origina uma interação contínua e dinâmica entre eles, como mostra a Figura 3:

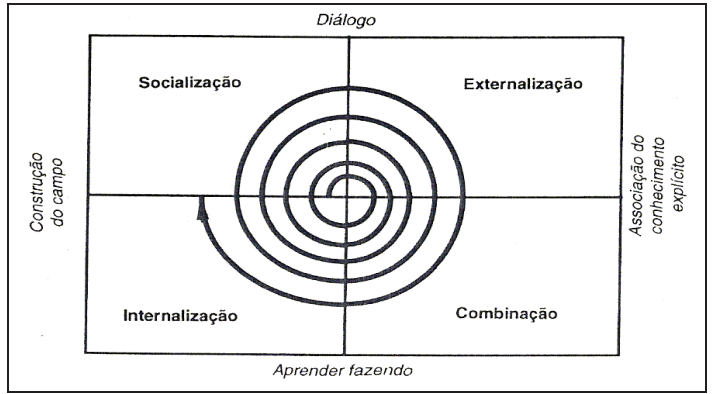

Figura 3 - Espiral do conhecimento Fonte: Nonaka e Takeuchi (1997, p. 80)

São os padrões básicos para a criação do $\mathrm{CO}$, descritos por Nonaka e Takeuchi (1997):

a) socialização: tácito em tácito - criação de conhecimento pela da observação, pela prática, pelo compartilhamento de experiências;

b) externalização: tácito em explícito - criação de conhecimento pela articulação do conhecimento tácito e sua transformação em conhecimento explícito;

c) combinação: explícito em explícito - criação de conhecimento pela combinação de dados, informações e conhecimentos;

d) internalização: explícito em tácito - criação de conhecimento pela comunicação de conhecimentos explícitos que são absorvidos pelas pessoas, entendidos e traduzidos em conhecimento tácito.

Davenport (1994) aponta o fato de que os conhecimentos interfuncionais das equipes facilitam a interface funcional e colaboram com a elaboração do planejamento, aumentando a probabilidade de que determinado produto atenda a exigências multifuncionais. Leonard (1995) infere que os processos de construção do conhecimento na empresa estão relacionados a quatro atividades, as quais são decisivas para construção do $\mathrm{CO}$ e consequentemente melhoram os produtos ou serviços da organização. São elas: compartilhamento da tarefa de análise e solução de problemas, envolvimento do cliente, experimentação e importação de conhecimentos. Tais atividades são evidenciadas na Figura 4: 


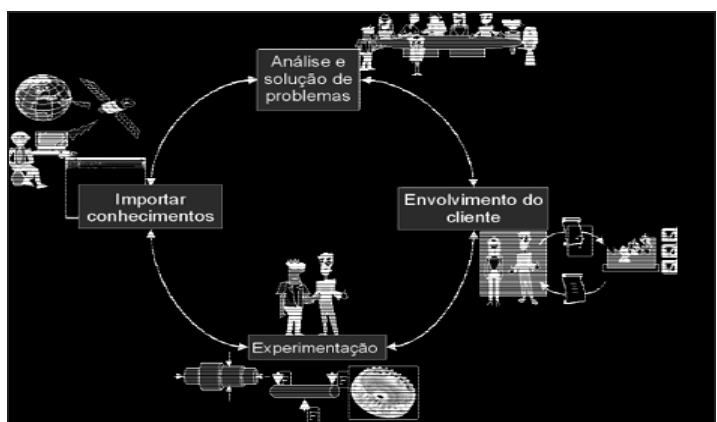

Figura 4 - Atividades para construção do conhecimento organizacional Fonte: Silva (2002, p. 143)

Para Silva (2002), que também discutiu as atividades propostas por Leonard (1995), a chave para construção do CO está na inter-relação das atividades. Para que haja o inter-relacionamento de uma atividade para com as demais, as mesmas precisam contemplar:

a) o compartilhamento da tarefa de análise e solução de problemas, ou seja, a preocupação está em reunir visões diferentes para análise e participação de pessoas para confrontação construtiva;

b) o envolvimento do cliente, de um modo que ele participe das decisões através de consultas periódicas;

c) a existência de um clima que tolere a experimentação e a visualização de soluções por intermédio da prática, como uma forma de assegurar o aprendizado da organização;

d) a absorção de conhecimentos do mercado (importar conhecimentos), desde a observação informal de alguma fonte, a realização de benchmarking, até a realização de alianças e jointventures.

As atividades propostas por Leonard (1995) estão intimamente ligadas à reunião de pessoas buscando a confrontação construtiva (creative abrasion). O aprendizado em grupo é o processo de desenvolvimento da capacidade de um grupo criar os resultados que seus membros realmente desejam (SENGE, 1998). Esse aprendizado possui três dimensões essenciais: a necessidade de analisar com discriminação as questões complexas tornando a inteligência do grupo maior que a individual; a necessidade de ações inovadoras oriundas das contribuições de todos, e a ligação de um grupo com outros grupos para troca de conhecimentos.

O aprendizado coletivo, evidenciado por Senge (1998), vem ao encontro das atividades expostas por Leonard (1995), já que os grupos ou equipes passam a aprender pelo trabalho e pela prática das atividades. Para Nonaka e Takeuchi (1997, p. 79), "a criação do conhecimento organizacional é uma interação contínua e dinâmica entre o conhecimento tácito e o conhecimento explícito", ou seja, entre o conhecimento intangível que está dentro das pessoas e o tangível, formal e documentado.

A preocupação no envolvimento dos recursos humanos para melhoramento de produtos e serviços vem ganhando espaço. No que tange a qualidade, dos oito critérios de excelência do Prêmio Nacional de 
Qualidade 2009, um deles trata especificamente de pessoas e faz parte do modelo de excelência da gestão que simboliza a organização como um sistema orgânico e adaptável, capaz de interagir constantemente com o ambiente externo.

O critério de pessoas examina como são proporcionadas as condições para aproveitamento do potencial das pessoas no trabalho para que as mesmas conduzam a excelência do desempenho e o crescimento pessoal em consonância com os objetivos organizacionais. Para tanto, são analisados três itens: a) os sistemas de trabalho: avalia a organização do trabalho; b) a capacitação e desenvolvimento: avalia como os programas de capacitação e desenvolvimento são definidos, e c) qualidade de vida: avalia como o clima organizacional é mantido propício ao bem-estar, à satisfação e à motivação das pessoas.

Neste contexto, em que as empresas dependem frequentemente do pessoal de "linha de frente" e o desempenho das pessoas torna-se importante na percepção do cliente sobre o serviço fica evidente a importância e o envolvimento das pessoas nos processos de produção, principalmente, quando o assunto é prestação de serviços (DIEHL, 2004).

Lovelock (1995) e Johnston e Clark (2002), entendem que serviços são as ações e reações que os clientes percebem que compraram. Assim, pode-se dizer que a percepção dos consumidores deve ser levada em consideração na prestação de serviços. Para Machado (2006, p. 262), entender o conceito de prestação de serviços é "de fundamental importância para a compreensão da natureza das atividades que envolvem a prestação de serviço". Segundo essa autora a prestação de serviços é bastante subjetiva, pois pode envolver uma atividade realizada em um produto tangível fornecido pelo cliente; uma atividade realizada em um produto intangível fornecido pelo cliente; a entrega de um produto intangível, e a criação de um ambiente agradável para o cliente.

Diante disso, o desafio está em prestar serviços com qualidade, pois os mesmos serviços podem não atender a diferentes consumidores. Para Slack, Chambers e Johnston (2002), a qualidade deve ser entendida do ponto de vista do consumidor, pois assim como os serviços, a qualidade é aquilo que ele entende ou percebe como qualidade. Ou seja, quando o serviço prestado não atinge às expectativas do cliente, há uma deficiência na qualidade como afirma Grönroos (1995).

Ações voltadas para todos na empresa merecem atenção, pois segundo Scholtes (1992), uma única pessoa usando práticas de melhoria da qualidade pode fazer diferença em uma organização, mas uma única pessoa não possui o conhecimento ou a experiência suficiente para compreender tudo o que está envolvido em um processo.

A utilização de equipes no ambiente de trabalho para melhorar a qualidade na produção de produtos e serviços, é tratada por alguns autores, como Townsend (1991), Sholtes (1992) e Martins e Laugeni (2001), com grande entusiasmo. Para esses autores os membros de equipes são comprometidos, a liderança é compartilhada, os membros das equipes trabalham em conjunto, estabelecem suas metas voltadas ao resultado e há soluções de problemas da qualidade. Para o envolvimento do ambiente 
produtivo com a qualidade são indispensáveis "ações consistentes, na área de recursos humanos, voltadas para o desenvolvimento e treinamento do pessoal bem como o encorajamento ao trabalho em times" (MARTINS e LAUGENI 2001, p. 395).

Na visão de Moscovici (2003) e Robbins (2001), a interação das pessoas em equipes podem se transformar em um diferencial competitivo importantíssimo ao ambiente empresarial. Para Katzenbach e Smith (2001), as equipes são peças fundamentais para o desempenho empresarial diante de um cenário de mudanças profundas, ou seja, as equipes, o desempenho delas, podem ser utilizadas como resposta às mudanças.

\section{Metodologia}

O método de pesquisa utilizado é o estudo de caso. Para Yin (2001), tratase de um método a ser utilizado quando da investigação empírica de um fenômeno dentro de seu contexto da vida real, explorando as condições entre o fenômeno e o contexto em que este está inserido.

Tendo como base o método de estudo de caso, foram adotados os seguintes procedimentos para o desenvolvimento da pesquisa: a) revisão bibliográfica; b) elaboração de entrevista semi-estruturada composta de questões abertas e com roteiro para condução da mesma; c) definição da população; d) entrevista; e) elaboração de questionários para as equipes e os gerentes; f) observação não participante; g) aplicação dos questionários; h) aplicação do instrumento de Dyer (1995) para apurar a maturidade das equipes e identificar as mesmas na curva de desempenho das equipes de Katzenbach e Smith (1994), e i) análise dos dados.

A empresa estudada é uma prestadora de serviços, de médio porte, que atua no transporte de passageiros no Estado do Paraná e utiliza a gestão baseada em equipes no setor operacional desde julho de 2005. A população foi composta de um universo de 4 gerentes e de 77 membros de equipes da empresa em estudo. Dois membros de equipe foram descartados, pois estavam participando da primeira reunião em suas equipes e entendeu-se que os mesmos não tinham experiência prática para responder os questionários.

A entrevista semi-estruturada foi aplicada a quatro gerentes da empresa. O objetivo da entrevista com o entrevistado 1 (E1) foi de caráter exploratório; com os demais (E2, E3 e E4) o objetivo foi verificar a participação das equipes na qualidade dos serviços prestados. Buscando melhorar a interpretação das respostas e dos registros na entrevista, utilizou-se, com a autorização dos entrevistados, um gravador. As gravações foram transcritas ipsis literis para facilitar a análise.

Em seguida, os questionários elaborados e o instrumento proposto por Dyer (1995) foram aplicados aos membros das equipes. Juntamente com a aplicação dos mesmos, as observações de caráter não participante buscaram registrar elementos de interesse para o cumprimento dos objetivos desta pesquisa.

Os questionários aplicados foram compostos de questões fechadas. O primeiro, com quatro questões, buscou a percepção das equipes em 
relação a qualidade e o segundo, com três questões, a percepção dos gerentes em relação ao trabalho das equipes e a qualidade. Junto ao questionário aplicado aos gerentes foi entregue a relação de equipes, numeradas com algarismos arábicos, e seus respectivos membros para identificação das mesmas.

O instrumento é composto de 15 perguntas voltadas aos principais itens que influenciam o desempenho das equipes e determinam sua qualificação quanto à maturidade do grupo. O instrumento é composto de alternativas baseadas na experiência de cada membro com sua equipe, em que o participante escolhe a resposta que melhor reflete seu grau de concordância ou discordância escolhendo uma nota na escala.

O primeiro questionário e o instrumento foram respondidos identificando somente a equipe a que pertence. O segundo questionário foi respondido e assim como os demais, depositados em urnas a fim de assegurar sigilo sobre suas opiniões e também estabelecer um clima de confiança e empatia (TRIVIÑOS, 1987).

Por fim, foi feita a triangulação dos dados obtidos nas entrevistas, nos questionários, no instrumento e nas observações não participantes. Para análise das observações participantes foi utilizada a análise de conteúdo que, segundo Minayo (2004), busca encontrar respostas para confirmar as hipóteses. Para tanto, foram organizados os materiais e separados por categorias de acordo com o referencial teórico para facilitar os processos de triangulação dos dados.

O questionário recebeu análise estatística simples identificando o percentual de "sim" e "não" em cada questão. O Instrumento de Dyer (1995) a soma das notas individuais (Mi), dividida pelo número de membros da equipe $(\mathrm{N})$, confere a pontuação à equipe, ou seja, o nível de maturidade do grupo (Mg). Após a apuração da maturidade do grupo foram verificados os parâmetros abaixo para uma avaliação aproximada do nível de maturidade da equipe e identificadas na curva de desempenho das equipes de Katzenbach e Smith (1994):

a) Pontuação igual ou acima de 3.75: evidencia um nível elevado de maturidade, identificando uma equipe real ou verdadeira. Quanto maior a pontuação, ou seja, mais próxima de cinco, maior probabilidade de que a equipe seja uma equipe de alta performance;

b) Pontuação entre 2.5 e 3.75 , indica um nível intermediário de maturidade, característicos das equipes potenciais e grupos de trabalho eficientes, e

c) Pontuação inferior a 2.5 indica um nível inadequado de maturidade, o que poderia ser indicativo de uma pseudo-equipe ou grupo de trabalho ineficiente.

Segundo Yin (2001, p. 121), "várias fontes de evidências fornecem essencialmente várias avaliações do mesmo fenômeno". Os procedimentos tiveram a intenção de aumentar a compreensão dos dados para análise e conclusões dos resultados. 


\section{Resultados}

As experiências pessoais e profissionais têm uma participação fundamental na maturidade das pessoas. As mesmas interagem ativamente na capacidade das pessoas assumirem responsabilidades e nas experiências vivenciadas. O grau de maturidade de grupos ou equipes de trabalho, em termos gerais, parece ser fundamental para uma melhora na qualidade de produtos ou serviços. A partir das experiências vividas, da maturidade que a pessoa tem ou não para desempenhar uma determinada tarefa, é que a qualidade de produtos ou serviços pode ser maximizada.

A Escala de Maturidade de Equipe, proposta por Dyer (1995), é um instrumento que dentro da seqüência evolutiva de funcionamento dos grupos permite identificar na curva de desempenho de Katzenbach e Smith (1994) o tipo provável de equipe e sua maturidade. Nas equipes em estudo os resultados obtidos com o instrumento foram:

\begin{tabular}{c|c|c|c|c|c|c|c}
\hline ESCALA & $\begin{array}{c}\text { Equipe } \\
1\end{array}$ & $\begin{array}{c}\text { Equipe } \\
2\end{array}$ & $\begin{array}{c}\text { Equipe } \\
3\end{array}$ & $\begin{array}{c}\text { Equipe } \\
4\end{array}$ & $\begin{array}{c}\text { Equipe } \\
5\end{array}$ & $\begin{array}{c}\text { Equipe } \\
6\end{array}$ & $\begin{array}{c}\text { Equipe } \\
7\end{array}$ \\
\hline $\begin{array}{c}\text { inferior à } \\
2.5\end{array}$ & & & 2.47 & & & & \\
\hline $\begin{array}{c}\text { entre } 2.5 \text { e } \\
3.75\end{array}$ & 3.61 & 3.12 & & 3.31 & 3.47 & & \\
\hline $\begin{array}{c}\text { acima de } \\
3.75\end{array}$ & \multicolumn{7}{c}{ Tabela 1- Maturidade das equipes } \\
Fonte: os autores
\end{tabular}

Inicialmente, observa-se na Tabela 1 que uma provável pseudoequipe ou grupo de trabalho (equipe 3 ) foi identificada dentre as equipes em estudo. Segundo Katzenbach e Smith (1994) esses tipos de equipes podem definir um trabalho a se fazer, contudo não se preocupam com o desempenho. Para estes autores, os membros dessas equipes não vêem razão para se transformarem numa equipe.

Em seguida, foram identificadas quatro equipes (equipe 1, 2, 4 e 5) e classificadas como prováveis equipes potenciais. Esses tipos de equipes, segundo Katzenbach e Smith (1994), produzem trabalho conjunto, mas precisam de direcionamento sobre os objetivos individuais e da equipe.

Por fim, duas equipes (equipes 6 e 7), foram identificadas e classificadas como prováveis equipes real ou verdadeira. Segundo Dyer (1995), quanto maior a pontuação, ou seja, mais próxima de cinco, maior probabilidade de que a equipe seja uma equipe de alta performance. $\mathrm{Na}$ visão de Katzenbach e Smith (1994), essas equipes são comprometidas e os membros passam a confiar uns nos outros.

Paralelamente à aplicação do instrumento e dos questionários, as observações não participantes aconteceram. Na empresa em estudo, as observações permitiram identificar que as equipes possuem uma agenda de reuniões para compartilhamento de experiências e solução de problemas. $O$ ambiente mostrou-se favorável para a criação do conhecimento e 
desenvolvimento da aprendizagem coletiva, pois verificou-se no trabalho das equipes a prática de atividades voltadas para a construção do conhecimento organizacional. Essas atividades se assemelham às atividades propostas por Nonaka e Takeuchi (1997). É nas reuniões que acontece o compartilhamento de experiências (socialização), o registro dos conhecimentos e informações em atas (externalização) e a troca de conhecimentos (combinação). É a partir do trabalho diário que se efetiva a incorporação dos conhecimentos explícitos no conhecimento tácito (internalização).

Considerando que todas as equipes em estudo estão envolvidas em um ambiente igualmente propício para criação do conhecimento e favorável a melhoras na qualidade dos serviços prestados, pode-se inferir, utilizandose das nomenclaturas de Katzenbach e Smith (1994), que equipes com maior grau de maturidade desempenham serviços com melhor qualidade. Segundo esses autores, as equipes com melhor performance são comprometidas através da missão e objetivos comuns e isso pode caracterizar, na visão de Katzenbach (1999), produtos e serviços com alto valor agregado. A visão de Katzenbach (1999) é compartilhada por outros autores - Townsend (1991), Sholtes (1992) e Martins e Laugeni (2001) - ao relacionar grupos ou equipes como ferramenta para melhorar e manter a qualidade de produtos ou serviços.

A Tabela abaixo sumariza as diferentes percepções das equipes em relação ao trabalho das mesmas e à qualidade dos serviços prestados:

\begin{tabular}{|c|c|c|c|c|c|c|c|}
\hline \multirow[t]{2}{*}{$\begin{array}{c}\text { PERCEPÇÕES DAS } \\
\text { EQUIPES } \\
x \\
\text { QUALIDADE }\end{array}$} & 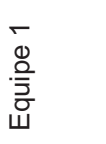 & $\begin{array}{l}N \\
0 \\
\frac{\varrho}{3} \\
\check{\sigma} \\
\dot{W}\end{array}$ & $\begin{array}{l}m \\
0 \\
\frac{\varrho}{3} \\
\frac{\partial}{\square}\end{array}$ & $\begin{array}{l}+ \\
\searrow \\
\frac{\varrho}{3} \\
\dot{\sigma} \\
\dot{W}\end{array}$ & $\begin{array}{l}\llcorner 0 \\
\searrow \\
\frac{\varrho}{3} \\
\frac{\partial}{\square}\end{array}$ & $\begin{array}{l}0 \\
\searrow \\
\frac{\varrho}{J} \\
\bar{\sigma} \\
\dot{W}\end{array}$ & 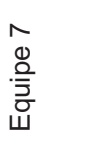 \\
\hline & \multicolumn{7}{|c|}{$\%$ RESPOSTAS POSITIVAS } \\
\hline $\begin{array}{l}\text { 1-Existência de } \\
\text { reclamações de clientes } \\
\text { em relação aos serviços } \\
\text { prestados pelas equipes. }\end{array}$ & 63.64 & 81.82 & 88.89 & 81.82 & 72.73 & 100.00 & 90.91 \\
\hline $\begin{array}{l}\text { 2-A qualidade dos } \\
\text { serviços prestados pela } \\
\text { equipe no ambiente } \\
\text { produtivo. }\end{array}$ & 81.82 & 90.91 & 100,00 & 100.00 & 90.91 & 72.73 & 63.64 \\
\hline $\begin{array}{l}\text { 3-O trabalho em equipe e } \\
\text { a contribuição na } \\
\text { qualidade dos serviços } \\
\text { da empresa. }\end{array}$ & 100.00 & 90.91 & 100.00 & 100.00 & 90.91 & 72.73 & 72.73 \\
\hline $\begin{array}{l}\text { 4-Mudanças para } \\
\text { melhorar a qualidade dos } \\
\text { serviços prestados e a } \\
\text { prática das mesmas. }\end{array}$ & 81.82 & 90.91 & 88,89 & 72.73 & 90.91 & 72.73 & 72.73 \\
\hline MÉDIA POR EQUIPE & 81.83 & 88.64 & 94.44 & 88.64 & 86.36 & 79.55 & 75.00 \\
\hline
\end{tabular}
Fonte: os autores

Observa-se na percepção dos membros das equipes, que nas equipes $1,2,3,4$ e 5 à existência de reclamações de clientes (item 1) é 
menor em relação a percepção das equipes 6 e 7. Essas últimas equipes, em relação à percepção do que diz respeito à qualidade dos serviços prestados pelas equipes e a contribuição das mesmas na qualidade dos serviços da empresa (respectivamente itens 2 e 3), observa-se menores médias caracterizando, em relação às demais equipes, que a qualidade deixa a desejar. $E$, em relação às mudanças para melhorar a qualidade dos serviços prestados e a prática das mesmas (item 4), visualiza-se um quadro em que as equipes 4, 6 e 7 são as que menos acreditam na prática das mudanças sugeridas pelas equipes.

Tomando como base a classificação das equipes em estudo (Tabela 1) e as percepções das equipes em relação à qualidade dos serviços prestados (Tabela 2), observa-se que as equipes com maior grau de maturidade (6 e 7) têm percepções que sugerem que as mesmas deixam a desejar no que diz respeito à contribuição do trabalho em equipes para com a qualidade. Resultados divergentes são encontrados nas equipes com maturidade mais baixa que as equipes 6 e 7 .

Esses resultados são melhores entendidos nas respostas dos gerentes ao questionário que avaliou a percepção dos mesmos em relação às equipes e durante as entrevistas. Os resultados dos questionários aos gerentes evidenciaram percepções diferentes as das equipes:

\begin{tabular}{|c|c|c|c|c|c|c|c|}
\hline $\begin{array}{c}\text { PERCEPÇÕES DOS } \\
\text { GERENTES } \\
x \\
\text { EQUIPES E } \\
\text { QUALIDADE }\end{array}$ & 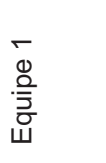 & $\begin{array}{l}N \\
0 \\
\frac{\varrho}{3} \\
\frac{\sigma}{W}\end{array}$ & 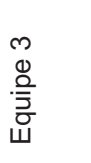 & 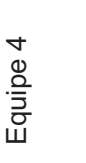 & 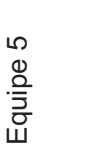 & $\begin{array}{l}0 \\
0 \\
\frac{\partial}{J} \\
\frac{\partial}{\sigma}\end{array}$ & 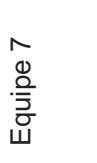 \\
\hline & \multicolumn{7}{|c|}{ \% RESPOSTAS POSITIVAS } \\
\hline $\begin{array}{l}\text { 1-A qualidade dos } \\
\text { serviços prestados pela } \\
\text { equipe no ambiente } \\
\text { produtivo. }\end{array}$ & 66.67 & 33.33 & 66.67 & 66.67 & 100.00 & 100.00 & 66.67 \\
\hline $\begin{array}{l}\text { 2-O trabalho da equipe e } \\
\text { a contribuição na } \\
\text { qualidade dos serviços } \\
\text { da empresa. }\end{array}$ & 66.67 & 66.67 & 66.67 & 66.67 & 66.67 & 100.00 & 100.00 \\
\hline $\begin{array}{l}\text { 3-Mudanças para } \\
\text { melhorar a qualidade dos } \\
\text { serviços prestados e a } \\
\text { prática das mesmas. }\end{array}$ & 100.00 & 66.67 & 33.33 & 66.67 & 66.67 & 100.00 & 100.00 \\
\hline MÉDIA POR EQUIPE & 77.78 & 55.56 & 55.56 & 66.67 & 77.78 & 100.00 & 88.89 \\
\hline
\end{tabular}
Fonte: os autores

Os resultados da Tabela 3 , em relação aos das Tabelas 2 e 1, refletem que as equipes com melhor grau de maturidade (equipes 6 e 7) na percepção dos gerentes são as que melhor contribuem para a qualidade dos serviços prestados pela empresa. Na percepção dos membros dessas equipes, os resultados demonstram-se divergentes, pois as equipes 6 e 7 têm percepções as quais sugerem que as mesmas não estão contribuindo tanto para a qualidade dos serviços prestados quanto às demais equipes. 
A equipe 3, por exemplo, foi classificada na Escala de Maturidade de Dyer (1995) como uma provável pseudo-equipe ou grupo de trabalho (Tabela 1) e apresenta, segundo as percepções de seus membros, os melhores resultados na Tabela 2, que resume a participação das equipes na qualidade dos serviços prestados. Em contrapartida, na percepção dos gerentes (Tabela 3 ) é, junto com a equipe 2, a equipe que menos agrega para qualidade dos serviços prestados.

Os resultados da equipe 3 (Tabelas 1, 2 e 3) podem estar associados à baixa ou moderada maturidade, pois segundo Hersey e Blanchard (1986), baixa ou moderada maturidade (M1 e M2) são comuns em pessoas que não têm capacidade e que pode ou não sentir vontade de assumir a responsabilidade de fazer algo. Neste sentido, a equipe 3 ainda não está prestando atenção na sua forma de trabalhar e resolver os problemas que afetam seu funcionamento nem em transformar-se em uma equipe como cita Moscovici (2003).

As entrevistas mostraram o quanto os gerentes da empresa confiam no trabalho das equipes para melhorar a qualidade dos serviços prestados. Nos fragmentos das respostas do declarante E2, visualiza-se melhor o quadro: "Olha, o que se tem notado realmente é que há usuários que realmente já estão 'até parabenizado' pelas atitudes dos funcionários, acredito então que está surgindo algum efeito sobre isso". Para o declarante E4 "No momento alguma coisa [...] já apareceu, mas lógico com o tempo é que com certeza vai melhorar essa situação".

Contudo, nota-se também que existem problemas que podem prejudicar a qualidade dos serviços prestados, como mostra os fragmentos abaixo:

a) "[...] a gente vê ainda muita falha no pessoal, mas 'devagarinho tá indo'” (E2).

b) "[...] 'tá' sendo colocado em prática, mas tem ainda algumas que não 'tão' sendo colocadas, às vezes por negligência ou por falta de vontade deles [...]" (E3).

c) "Acho que cai bastante também, um pouco, no esquecimento, acredito que acompanhá-lo mais de perto para que isto seja feito" (E4).

As respostas acima demonstram que em termos gerais as equipes apresentam problemas, mas que tendem a desaparecer quanto o nível de maturidade das mesmas for maior. Para o declarante E3, a maioria das decisões que está sendo tomada no trabalho em equipe está sendo colocada em prática e isso é um fator positivo. Para alguns autores Sacomano Neto e Escrivão Filho (2000), Salomão (1999) e Moscovici (2003) - as equipes devem contemplar objetivos comuns ao compartilhamento de competências e de esforços para que as metas ou objetivos sejam cumpridas.

\section{Considerações finais}

Os resultados deste estudo de caso permitiram identificar a influência da maturidade da equipe na qualidade dos serviços da empresa em estudo. $O$ 
primeiro implicativo que caracteriza esta influência é evidenciado com as diferentes percepções sobre o trabalho em equipe e a qualidade, das equipes e dos gerentes.

De um lado, equipes com maior grau de maturidade (6 e 7) e com percepções das quais sugerem que as mesmas deixam a desejar no que diz respeito a contribuição do trabalho em equipes para com a qualidade da empresa. E, de outro, gerentes que acreditam que estas equipes são as que mais contribuem com seus trabalhos para a qualidade dos serviços prestados pela empresa. Embora os membros das equipes com maior maturidade (6 e 7) não concordem que estejam contribuindo efetivamente para qualidade dos serviços prestados, seus gerentes atribuíram que essas equipes são as que mais contribuem.

O segundo implicativo que evidencia a influência são as entrevistas com os gerentes E2, E3 e E4. As entrevistas, além de evidenciarem a confiança da empresa no trabalho das equipes e alguns resultados positivos como a manifestação de clientes, mostraram que algumas equipes estão participando mais ativamente e fazendo com que a qualidade dos serviços prestados seja influenciada.

A gestão baseada em equipes como ferramenta para melhorar a qualidade dos serviços prestados e favorecer mudanças voltadas à competitividade vem ao encontro com as atuais necessidades empresariais relatadas por Claver-Cortés et al. (2007): a busca por estruturas mais flexíveis no ambiente laboral é eminente. Não obstante, observa-se a importante participação de um ambiente favorável ao compartilhamento de experiências e, sobretudo, da maturidade das equipes que se mostrou um elemento de influência sobre a qualidade dos serviços prestados pela empresa em exame.

\section{Referências}

BEJARANO, V. C. Elementos Essenciais à Implementação de Equipes: um estudo de caso da indústria de papel. 2006. 115f. Dissertação (Mestrado em Engenharia da Produção) - Programa de Pós-Graduação em Engenharia de Produção, UTFPR, Ponta Grossa.

BEJARANO, V. C.; PILATTI, L. A. Elementos Externos Essenciais à Implementação de Equipes: um estudo de caso. Revista de Administração. São Paulo, v.43. n.1. p. 17-29, jan/fev/mar. 2008.

CLAVER-CORTÉS, E. et al. Organizational Structure Features Supporting Knowledge Management Processes. Journal of Knowledge Management. v. 11. n. 4. p. 45-57. 2007.

DAVENPORT, T. H. Reengenharia de Processos: como inovar na empresa através da tecnologia da informação. 2. ed. Rio de Janeiro: Campus, 1994. 
DIEHL, C. A. Controle Estratégico de Custos: um modelo referencial avançado. 2004. 304 f. Tese (Doutorado em Engenharia de Produção) Centro Tecnológico, Universidade Federal de Santa Catarina, Florianópolis.

DRUCKER, P. F. Administrando em Tempos de Grandes Mudanças. Editora Pioneira Thomsom Learning. São Paulo, 2001.

DRUCKER, P. Peter Drucker na Prática. Rio de Janeiro: Elsevier, 2004.

DYER, W. Team Building. 3. ed. New York: Addison-Wesley Publishing Company Inc, 1995.

FISHER, S. G. et al. Team or Group? Managers' perceptions of the differences. Journal of Managerial Psychology. v. 12. n. 4. p. 232-242. 1997.

FUNDAÇÃO PRÊMIO NACIONAL DE QUALIDADE. Critérios de Excelência. Disponível em: http://www.fpnq.org.br/site/402/default.aspx Último acesso em 20 abr 2009.

FLEURY, M.T.L.; OLIVEIRA, M. M. J. Gestão Estratégica do Conhecimento: integrando aprendizagem, conhecimento e competências. São Paulo: Atlas, 2001.

GIL, A. C. Métodos e Técnicas de Pesquisa Social. São Paulo: Atlas, 1999.

GRÖNROOS, C. Marketing, Gerenciamento e Serviços: a competição por serviços na hora da verdade. Rio de Janeiro, Campus, 1995.

HERSEY, P.; BLANCHARD, K. H. Psicologia para Administradores: as teorias e as técnicas da liderança situacional. São Paulo: EPU, 1986.

JOHNSTON, R.; CLARK, G. Administração de Operações de Serviços. São Paulo: Atlas, 2002.

LEONARD, D. Wellspring of Knowledge. Boston: Harvard Business School, 1995.

LOVELOCK, C. Product Plus: produto+serviço=vantagem competitiva. São Paulo: Makron Books, 1995.

KATZENBACH, J. R.; SMITH, D. K. A Força e o Poder das Equipes. São Paulo: Makron, 1994.

KATZENBACH, J. R.; SMITH, D. K. Equipes de Alta Performance: conceitos, princípios e técnicas para potencializar o desempenho das equipes. Rio de Janeiro: Campus, 2001. 
MACHADO, M. D. et al. Mensuração da Qualidade de Serviços em Empresas de Fast Food. Gestão \& Produção, São Carlos, Mai-Ago, v.13 n.2, p.261-270, 2006.

MARTINS, P. G.; LAUGENI, F. P. Administração da Produção. São Paulo: Saraiva, 2001.

MINAYO, M. C. S. Pesquisa Social: teoria, método e criatividade. 23. ed. Petrópolis: Editora Vozes, 2004.

MONTANARI, R. L. Os Homens e as Equipes de Trabalho no Ambiente Produtivo. 2008. 187f. Dissertação (Mestrado em Engenharia da Produção) - Programa de Pós-Graduação em Engenharia de Produção, UTFPR, Ponta Grossa.

MOSCOVICI, F. Equipes dão Certo: a multiplicação do talento humano. 8. ed. Rio de Janeiro: José Olympio, 2003.

NONAKA, I.; TAKEUCHI, H. Criação de Conhecimento na Empresa. Tradução: Ana Beatriz Rodrigues e Priscila Martins Celeste. 12. ed. Rio de Janeiro: Elsevier, 1997.

PARKER, G. M. O Poder das Equipes. Rio de Janeiro: Campus, 1995.

ROBBINS, S. P. Administração: mudanças e perspectivas. São Paulo: Saraiva, 2001.

SACOMANO N. M.; ESCRIVAO Filho, E. Estrutura organizacional e equipes de trabalho: estudo da mudança organizacional em quatro grandes empresas industriais. Gestão \& Produção, São Carlos, Ago, v.7, n.2, p.136-145, 2000.

SALOMÃO, M. A. Desenvolvimento de Equipes. In: BOOG, G. G. [org.] Manual de Treinamento e Desenvolvimento. Associação Brasileira de Treinamento e Desenvolvimento. 3. ed. São Paulo: Makron Books, 1999. Cap. Desenvolvimento de Equipes. p. 507-532.

SENGE, P. A Quinta Disciplina: arte e prática da organização que aprende. 3. ed. São Paulo: Best Seller, 1998.

SILVA, S. L. Informação e Competitividade: a contextualização da gestão do conhecimento nos processos organizacionais. Ciência da Informação, maio/ago, vol.31, n.2, p.142-151. 2002.

SILVA, U. B.; KOVALESKI, J. Desenvolvimento de Equipe Através da Liderança Situacional e Feedback $360^{\circ}$ - caso de uma equipe de manutenção da Copel Distribuição S.A, Superintendência de Distribuição 
Centro-sul. In: Encontro Nac de Eng de Produção, XXVI, 2006, Fortaleza. Anais ... Fortaleza: ABEPRO, 2006. p. 1-9.

SHOLTES, P. R. Times da Qualidade: como usar equipes para melhorar a qualidade. Rio de janeiro: Qualitymark, 1992.

SLACK, N.; CHAMBERS, S.; JOHNSTON, R. Administração da Produção. Trad. Maria Teresa Corrêa de Oliveira e Fábio Alther. 2. ed. São Paulo: Atlas, 2002.

TOWNSEND, P. Compromisso com a Qualidade. Rio de janeiro: Campus, 1991.

TRIVIÑOS, A. Introdução à Pesquisa em Ciências Sociais. São Paulo: Atlas, 1987.

YIN, R. K. Estudo de Caso: planejamento e métodos. 2. ed. Porto Alegre: Bookman, 2001. 